\title{
Chronic pelvic pain in women: comparative study between ultrasonography and laparoscopy as diagnostic tool
}

\author{
Rajani Rawat ${ }^{1}$, Shikha Seth ${ }^{1}$, Ramakant Rawat ${ }^{2}$, \\ Ruchika Garg $^{3}$, Sushil Shukla ${ }^{4}$, Soniya Vishwakarma ${ }^{1}$
}

\begin{abstract}
${ }^{1}$ Department of Obstetrics \& Gynaecology, UP Rural Institute of Medical Science and Research, Saifai, Etawah, Uttar Pradesh, India, ${ }^{2}$ Department of Medicine, UP Rural Institute of Medical Science and Research, Saifai, Etawah, Uttar Pradesh, India, ${ }^{3}$ Department of Obstetrics \& Gynaecology, Sarojini Naidu Medical College, Agra, Uttar Pradesh, India, ${ }^{4}$ Department of Social and Preventive Medicine, UP Rural Institute of Medical Science and Research, Saifai, Etawah, Uttar Pradesh, India
\end{abstract}

Received: 21 September 2014

Accepted: 10 October 2014

\author{
*Correspondence: \\ Dr. Rajani Rawat, \\ E-mail: rajanirawat21@gmail.com
}

Copyright: () the author(s), publisher and licensee Medip Academy. This is an open-access article distributed under the terms of the Creative Commons Attribution Non-Commercial License, which permits unrestricted non-commercial use, distribution, and reproduction in any medium, provided the original work is properly cited.

\begin{abstract}
Background: Chronic pelvic pain is a major cause of morbidity among the reproductive age group women. The study on patients of chronic pelvic pain aimed to compare the diagnostic accuracy of ultrasonography and laparoscopy in these patients

Methods: The study was conducted on 100 patients of chronic pelvic pain attending the gynaecology outdoor and were subjected to thorough clinical examination followed by ultrasonography and laparoscopic examination.

Results: Maximum number of cases of chronic pelvic pain belonged to 25-30 years, were parous with mean duration of pain of 15.2 months. The most common complaint was vaginal discharge (70\%) followed by menstrual irregularity. On clinical examination, pelvic tenderness was observed in majority $(60 \%)$ of cases. USG examination showed chronic pelvic inflammatory disease in $43 \%$ cases followed by myoma (8\%), ovarian cyst (5\%), endometriosis $(6 \%)$, pelvic congestion (5\%) and no abnormal pathology in $25 \%$ cases. On laparoscopic examination, chronic pelvic inflammatory disease was present in $47 \%$ cases followed by endometriosis (11\%), pelvic congestion $(8 \%)$, myoma (8\%), adhesions $(7 \%)$ while $13 \%$ cases showed normal findings.

Conclusions: Laparoscopy is more effective than ultrasonography as a diagnostic tool in patients of chronic pelvic pain.
\end{abstract}

Keywords: Chronic pelvic pain, Laparoscopy, Pelvic inflammatory disease, Ultrasonography

\section{INTRODUCTION}

Chronic pelvic pain (CPP) is a common complaint among women, particularly in the reproductive age group (Jamieson, 1996). Chronic pelvic pain contributes to $10 \%$ of all OPD patients to a gynaecologist and over $40 \%$ of all laparoscopies performed by gynaecologist. ${ }^{1}$ Chronic pelvic pain is also responsible for approximately $20 \%$ of hysterectomies performed for benign disease. ${ }^{2}$
RCOG has proposed the definition of chronic pelvic pain as intermittent or constant pain in the lower abdomen or pelvis of atleast six months duration, not occurring exclusively with menstruation or intercourse and not associated with pregnancy. It is a symptom, not a diagnosis. ${ }^{3}$

There may be numerous somatic and visceral disorders that cause chronic pelvic pain. Potential visceral sources of chronic pelvic pain include the reproductive, genitourinary and gastrointestinal tracts, and potential 
somatic sources include the pelvic bones, ligaments, muscles and fascia. It may also be due to psychological disorders and neurological diseases, both central and peripheral. Cases of CPP are both gynaecological and non-gynaecological and in around $35 \%$ cases no cause is detected. Various gynaecological causes responsible for CPP are endometriosis, Pelvic Inflammatory Disease (PID), adhesions, pelvic congestion syndrome, adenomyosis, ovarian neoplasm, ovarian remnant, residual syndrome and leiomyoma.

Ultrasonography (USG) is an important non-invasive diagnostic tool for CPP. It plays a pivotal role in directing the patient to surgical or medical consultation or just watchful waiting. Laparoscopy allows direct visualization of abdominal and pelvic organs and also allows operative intervention to be done.

In the present study, we compared the USG and laparoscopy as diagnostic modalities of CPP.

\section{METHODS}

This prospective comparative study was conducted on 100 patients attending the gynaecology OPD. Women aged between 18-50 years and having pain in the lower abdomen of atleast 6 months duration, not associated with menstruation or sexual intercourse were included in the study. Exclusion criteria were: age $<18$ years and $>50$ years, pregnancy and its related causes, acute pelvic infection, history of non-gynaecological cause of chronic pelvic pain, pelvic organ prolapse, malignancy, congenital and acquired spinal deformities and those unfit for laparoscopy and anaesthesia.

A careful clinical history was taken regarding site, duration, nature and radiation of pain to other sites, aggravating and relieving factors, association with menstrual cycle and dyspareunia and other associated complaints. Proper menstrual history, obstetric history, medical and surgical history was also taken. Detailed past history of tuberculosis, haemorrhoids, fissure, polyp, urinary tract infection, nephrolithiasis, trauma, sexual abuse, known psychiatric problem was taken. All women underwent a general physical examination and systemic examination including per abdominal examination for any palpable mass in pelvis or hernia sites, tenderness in pelvis, pain in right iliac fossa (appendicitis) and examination of spine and joints to rule out musculoskeletal causes of chronic pelvic pain. Per speculum, per vaginal and bimanual pelvic examination was done to rule out organic pelvic lesion.

Routine blood investigations were done like, complete blood count, ESR, mantoux, urine pregnancy test, urine routine and microscopic examination. Stool examination (GI infestations), urine culture and sensitivity (UTI) and X-Ray KUB region (urolithiasis) was done. Pap smear and high vaginal swab or endocervical swab was taken for all women to rule out reproductive tract infections.

All cases were first subjected to USG examination, transabdominal followed by trans-vaginal ultrasound where thorough examination of uterus, ovaries, adnexae and pouch of Douglas was done. The cases were further subjected to laparoscopic examination. On laparoscopy, assessment was done regarding size, shape, mobility, condition/morphology of pelvic organs, any adhesions (if present-flimsy/dense), evidence of endometriosis, pouch of Douglas. The clinical history, examination and ultrasound findings were compared with diagnostic laparoscopy and subjected to statistical analysis.

\section{RESULTS}

Maximum number of cases of CPP belonged to 25-30 years $(37 \%)$, were parous and belonged to middle socioeconomic status $(55 \%)$ (Table 1$)$. It was observed that $63 \%$ cases had constant pelvic pain that was present in both the right and left iliac fossa. The mean duration of pain was 15.24 months. The patients of chronic pelvic pain had associated complaints, most common being vaginal discharge followed by menstrual irregularity (Table 2).

Table 1: Chronic pelvic pain case distribution.

\begin{tabular}{|c|c|c|}
\hline Parameters & $\begin{array}{l}\text { No. of } \\
\text { cases }\end{array}$ & $\begin{array}{l}\text { Percentage } \\
\%\end{array}$ \\
\hline \multicolumn{3}{|l|}{ Age } \\
\hline$<20$ years & 3 & 3 \\
\hline $20-25$ years & 12 & 12 \\
\hline $25-30$ years & 37 & 37 \\
\hline $30-35$ years & 28 & 28 \\
\hline$>35$ years & 20 & 20 \\
\hline \multicolumn{3}{|l|}{ Parity } \\
\hline $\mathrm{P} 0+0$ & 30 & 30 \\
\hline $\mathrm{P} 0+1$ & 6 & 6 \\
\hline $\mathrm{P} 1+0$ & 40 & 40 \\
\hline $\mathrm{P} 2+0$ & 13 & 13 \\
\hline$>\mathrm{P} 3+0$ & 11 & 11 \\
\hline \multicolumn{3}{|c|}{ Socio-economic status } \\
\hline Class IV \& V & 30 & 30 \\
\hline Class II \& III & 55 & 55 \\
\hline Class I & 15 & 15 \\
\hline \multicolumn{3}{|c|}{ Pain character } \\
\hline Constant & 63 & 63 \\
\hline Intermittent & 30 & 30 \\
\hline Episodic & 7 & 7 \\
\hline \multicolumn{3}{|c|}{ Duration of pain } \\
\hline 6-12 months & 32 & 32 \\
\hline 12-18 months & 23 & 23 \\
\hline 18-24 months & 20 & 20 \\
\hline 24-30 months & 4 & 4 \\
\hline 30-36 months & 11 & 11 \\
\hline
\end{tabular}


Table 2: Associated complaints.

\begin{tabular}{|lll|}
\hline Associated complaints & $\begin{array}{l}\text { No. of } \\
\text { cases* }\end{array}$ & $\begin{array}{l}\text { Percentage } \\
\%\end{array}$ \\
\hline Vaginal discharge & 70 & 70 \\
\hline Menstrual irregularity & 41 & 41 \\
\hline Dyspareunia & 39 & 39 \\
\hline Backache & 29 & 29 \\
\hline Dysmenorrhoea & 25 & 25 \\
\hline Infertility & 36 & 36 \\
\hline
\end{tabular}

*More than one associated symptoms were present in patients of CPP

Clinical examination of cases showed that pelvic tenderness was present in $60 \%$, distinct mass in $24 \%$, adnexal thickening in $26 \%$, cul-de sac nodularity in $15 \%$ and fixed uterine retroversion in $10 \%$. However, $18 \%$ cases showed no specific pelvic finding (Table 3 ).

Table 3: Findings on pelvic examination.

\begin{tabular}{|lll|}
\hline Pelvic findings & $\begin{array}{l}\text { No. of } \\
\text { cases* }\end{array}$ & $\begin{array}{l}\text { Percentage } \\
\%\end{array}$ \\
\hline Pelvic tenderness & 60 & 60 \\
\hline Cul-de sac nodularity & 15 & 15 \\
\hline Distinct mass & 24 & 24 \\
\hline Adnexal thickening & 26 & 26 \\
\hline Fixed uterine retroversion & 10 & 10 \\
\hline No specific abnormality & 18 & 18 \\
\hline
\end{tabular}

*More than one pelvic findings were present in patients of CPP

On USG examination (Table 4), majority of the cases (43\%) had Chronic PID (presence of regularly enlarged uterus, tubo-ovarian masses, hydro-salphinx or fluid in pouch of Douglas). Others like myoma (8\%), ovarian cyst $(5 \%)$, endometriosis $(6 \%)$, pelvic congestion $(5 \%)$ and adhesions (4\%) were also observed. No abnormal pathology was detected in $25 \%$ cases on USG examination.

Table 4: Comparison between USG and laparoscopy findings.

\begin{tabular}{|lllll|}
\hline \multirow{2}{*}{ Diagnosis } & \multicolumn{2}{l}{ Ultrasonography } & \multicolumn{2}{l|}{ Laparoscopy } \\
& Number & $\mathbf{\%}$ & Number & \% \\
\hline Chronic PID & 43 & 43 & 47 & 47 \\
\hline Endometriosis & 6 & 6 & 11 & 11 \\
\hline Myoma uterus & 8 & 8 & 8 & 8 \\
\hline Adhesions & 4 & 4 & 7 & 7 \\
\hline Ovarian cyst & 5 & 5 & 6 & 6 \\
\hline Pelvic congestion & 5 & 5 & 8 & 8 \\
\hline Normal & 25 & 25 & 13 & 13 \\
\hline
\end{tabular}

On laparoscopic examination (Table 4), 13\% of cases showed no pelvic pathology. Chronic PID was found in majority $(47 \%)$ of the cases evidenced by presence of regularly enlarged uterus with tubo-ovarian masses, hydro-salpinx, tortuous tubes or fluid in pouch of Douglas as well as presence of congested adnexa. Endometriosis evidenced by presence of endometriotic implants or nodules and endometriotic or chocolate cyst was present in $11 \%$ cases. Pelvic congestion (8\%), myoma (8\%), adhesions $(7 \%)$ and ovarian cyst $(6 \%)$ were also observed.

On comparing the findings of USG and laparoscopy, it is clearly evident that laparoscopy was more sensitive and specific in diagnosing the etiology of chronic pelvic pain as compared to USG. On applying $\mathrm{z}$ test for assessing the significance of laparoscopy over USG, it was found to be statistically significant $(\mathrm{P}$ value $=0.031)$.

Table 5: Co-relation between ultrasonography and laparoscopy.

\begin{tabular}{|lll|}
\hline & $\begin{array}{l}\text { Pathology } \\
\text { detected }\end{array}$ & $\begin{array}{l}\text { No pathology } \\
\text { detected }\end{array}$ \\
\hline Ultrasonography & 75 & 25 \\
\hline Laparoscopy & 87 & 13 \\
\hline
\end{tabular}

$P$ value $=0.031$

\section{DISCUSSION}

The mean age of the patient in our study was 30 years which is comparable to the study by Magni et al. ${ }^{4}$ (28.7 years). Maximum number of cases were from middle class $(55 \%)$ followed by lower social class $(30 \%)$. This is because our study was carried out in government hospital in which mostly people were from middle and lower class. Majority of the patients presented with the associated complaints of vaginal discharge $(70 \%)$ which is in close approximation with Malti Rohatgi et al. ${ }^{5}$ In our study, pelvic tenderness $(60 \%)$ was the most frequent pelvic finding which are closely related with the findings of Goldstein et al. ${ }^{6}$ who examined patients of CPP and found pelvic tenderness in $65 \%$ cases.

Clinical examination alone is not conclusive in the evaluation of patients of CPP, hence there arises a need for imaging the pelvic organ by USG or for direct visualization of pelvic organs by laparoscopy as suggested by Kamilya $\mathrm{G}^{7}$ et al and $\mathrm{Kang} \mathrm{SB}^{8}$ et al.

In our study, all cases were subjected to USG followed by laparoscopy. On USG examination, $75 \%$ cases had abnormal pathological findings and $25 \%$ cases had normal pelvic findings. Ozaksit $\mathrm{G}$ et al. ${ }^{9}$ in their study on chronic pelvic pain found USG to be normal in $13.3 \%$ cases.

The commonest laparoscopic diagnosis in our study was chronic PID (47\%) which is the most common cause of CPP in developing countries like India. Studies done in western countries have found endometriosis as the most common finding. Laparoscopic examination showed 
normal findings in $13 \%$ cases in our study as compared to $24 \%$ by Kontoravdis et al. ${ }^{10}$ Our findings are co-related with Donald Goldstein et al. ${ }^{6}$ who found abnormal pathology in $90 \%$ patients of CPP on laparoscopy.

In our study, laparoscopy was found to be more effective in diagnosing CPP as compared to USG and it was found to be statistically significant ( $\mathrm{P}$ value $<0.05$ ).

\section{CONCLUSION}

Chronic pelvic pain is a syndrome in which biological and psychosexual factors play role. Accuracy of clinical examination is limited by the presence of objective signs and symptoms. USG, being a non-invasive method, is the first modality for diagnosing CPP but many a times, cause is missed and in those not responding to treatment, laparoscopy is the method of choice. The present study indicates that laparoscopy is an excellent tool in evaluation of patients with chronic pelvic pain and has an added advantage of simultaneous performance of operative interventions if required. Recently, laparoscopic pain mapping under local anaesthesia and sedation appears to be promising to improve the accuracy of laparoscopy as a diagnostic tool in CPP.

Funding: No funding sources

Conflict of interest: None declared

Ethical approval: Not required

\section{REFERENCES}

1. Reiter RC. Chronic pelvic pain. Clin Obstet Gynaecol. 1990;33:130-6.

2. Howard FM. The role of laparoscopy in chronic pelvic pain: promise and pitfalls. Obstet Gynaecol. 1993;48:357-87.

3. Zondervan KT, Yudkin PL, Vessey MP, Dawes MG, Barlow DH, Kennedy SH. Prevalence and incidence of chronic pelvic pain in primary care: evidence from a national general practice database. $\mathrm{Br} \mathrm{J}$ Obstet Gynaecol. 1999;106:1149-55.

4. Magni G, Salmi A, Delco D, Coela A. Chronic pelvic pain and depression. Psychopathology. 1984; 17:132.

5. Rohatgi M. Pelvic pain. Indian J Obstet Gynaecol 1971;21:226.

6. Goldstein DP, Decholnoky C, Emans SI. Laparoscopy in the diagnosis and management of pelvic pain in adolescents. $\mathrm{J}$ Reprod Med. 1980;24:251-6.

7. Kamilya Gourishankar, Mukherji Joydev, Gayen Abhimanyu. Different methods for evaluation of chronic pelvic pain. J Obstet Gynaecol India. 2005 May/Jun;55(3):251-3.

8. Kang SB, Ching HH, Lee JY, Chang YS. Impact of diagnostic laparoscopy on management of chronic pelvic pain. J Sing Endosc. 2007;21(6):916-9.

9. Ozaksit G, Caglar T, Zorlu CG, Cobanoglu O, Cicek $\mathrm{N}$, Batioglu $\mathrm{S}$, et al. Chronic pelvic pain in adolescent women. Diagnostic laparoscopy and ultrasonography. J Reprod Med. 1995;40(7):500-2.

10. Kontoravdis A, Chryssikropoulos A, Hassiakos D, Liapis A, Zourlas PA. The diagnostic value of laparoscopy in 2365 patients with acute and chronic pelvic pain. Int J Obstet Gynaecol. 1996;52:243-8.

DOI: $10.5455 / 2320-1770 . i j r \operatorname{cog} 20141224$

Cite this article as: Rawat R, Seth S, Rawat R, Garg R, Shukla S, Vishwakarma S. Chronic pelvic pain in women: comparative study between ultrasonography and laparoscopy as diagnostic tool. Int J Reprod Contracept Obstet Gynecol 2014;3:9981001. 